\title{
O turismo em Cabo Verde no semanário O Arquipélago (1962-1974)
}

\author{
Eduarda Rovisco* \\ Instituto Universitário de Lisboa (Portugal)
}

\begin{abstract}
Resumo: Publicado entre agosto de 1962 e junho de 1974, o semanário O Arquipélago - órgão informativo do Centro de Informação e Turismo - espelhou a intensa campanha de promoção turística de Cabo Verde realizada neste período, tendo editado mais de duas centenas de artigos alusivos ao tema. Neste texto, são recenseados os principais eixos temáticos da estrutura narrativa destes artigos e examinados os propósitos e as fragilidades do projeto turístico desenhado para o arquipélago no período tardo-colonial português marcado pela guerra e pela propaganda alicerçada na retórica luso-tropicalista. Pretendendo constituir um contributo para o estudo do turismo em Cabo Verde no período colonial, este artigo revela que o arquipélago foi, nesta fase, descrito como uma montra da "nação luso-tropical" e testemunho do pretenso "clima de paz" e de "harmonia racial" do ultramar português.
\end{abstract}

Palavras-chave: Turismo; Colonialismo; Imprensa; Propaganda; O Arquipélago; Cabo Verde.

\section{Tourism in Cape Verde in the newspaper O Arquipélago (1962-1974)}

Abstract: Published between August 1962 and June 1974, the weekly newspaper, O Arquipélago - run by the Centro de Informação e Turismo (the Information and Tourism Centre) - mirrored Cape Verde's intense campaign to promote tourism during this period, with over two hundred articles on the theme. After identifying the main thematic axes of these articles' narrative structure, my text examines the aims and weaknesses of the tourist project designed for the archipelago in the Portuguese late colonial period marked by war and propaganda grounded in luso-tropicalist rhetoric. Aiming to contribute to the study of Cape Verde tourism in the colonial period, this article shows how the archipelago was presented as a showcase for the "luso-tropical nation" and as proof of the supposed "peace" and "racial harmony" of Portuguese colonies..

Keywords: Tourism; Colonialism; Press; Propaganda; O Arquipélago; Cape Verde.

Propriedade do Centro de Informação e Turismo (C.I.T.) ${ }^{1}$, O Arquipélago foi um semanário composto e impresso na Imprensa Nacional de Cabo Verde, com 619 números publicados entre 23/8/1962 e 20/6/1974 e o único periódico editado regularmente em Cabo Verde durante grande parte deste período (Brito-Semedo 2006: 175, 403; Fonseca 2014: 208-214). ${ }^{2}$ A sua criação, coincidente com a extinção do Notícias de Cabo Verde, foi impulsionada por Adriano Moreira, então Ministro do Ultramar, no decurso da sua visita à província. Até finais de maio de 1974, publicou-se, sob o título do semanário, a seguinte epígrafe com autoria atribuída a Adriano Moreira: "Estas terras de Cabo Verde parecem ter estado adormecidas, no meio do mar, desde a noite dos tempos, à espera de serem Portugal". A notícia com maior destaque no primeiro número do jornal reportava-se à visita do ministro, editando fragmentos do seu discurso, tais como: "recordo as gerações que transformaram estas ilhas de desertas numa continuação de Portugal, numa terra onde apenas trabalharam Deus e os Portugueses", "[e]stas ilhas são a vanguarda de Portugal nesta tão importante zona do Mundo e são como que os porta-bandeiras que precedem os exércitos". Neste artigo transcreveram-se ainda excertos dos discursos de receção proferidos pelas autoridades locais, como é o caso da prédica do Presidente da Câmara Municipal da Praia que terá terminado da

Centro em Rede de Investigação em Antropologia / Instituto Superior de Ciências do Trabalho e da Empresa - Instituto Universitário de Lisboa; E-mail: eduarda.rovisco@gmail.com 
seguinte forma: "Nada pedimos. Oferecemos as nossas vidas em defesa da Bandeira verde-rubra da integridade e da unidade da Pátria Portuguesa. Viva Portugal".

Estes fragmentos definem de modo exemplar a linha editorial do semanário colocado ao serviço da propaganda do regime, com um noticiário em grande parte circunscrito à agenda dos governos da metrópole e da província e aos projetos e inaugurações de infraestruturas. Arauto da propalada "missão civilizadora" de Portugal "pluricontinental, multirracial e multicultural", o jornal constituiu um compêndio de retórica luso-tropicalista, apresentando Cabo Verde como uma bandeira da miscigenação, da ausência de racismo e de "portuguesismo".

Contrariamente ao tema da guerra colonial, amiúde velado ou mencionado como tema subalterno, os títulos sobre turismo foram, regra geral, editados na primeira página. Ao longo dos 619 números publicados, contabilizei 224 artigos relativos ao turismo num crescendo contínuo até 1969 com 32 artigos. ${ }^{3}$ A partir de 1970 foi publicada uma média de 20 artigos por ano. Muitos destes 224 artigos são transcrições ou resumos de textos previamente publicados em periódicos da metrópole como o Diário de Lisboa, Diário Popular, Diário da Manhã, Diário de Notícias, Época, O Primeiro de Janeiro, O Século, República, a revista Permanência ou mesmo em periódicos estrangeiros como o Le Soir de Bruxelas ou o La Tarde das Canárias. ${ }^{4}$

Que imagem turística de Cabo Verde foi então construída e qual o seu propósito? Que projetos turísticos se desenharam neste período e que práticas foram descritas? São estas as principais questões que nortearam a pesquisa de que resultou este texto que constitui uma primeira aproximação ao estudo do turismo em Cabo Verde no período colonial e que será desenvolvida em termos diacrónicos. ${ }^{5}$ Este artigo encontra-se dividido em duas partes a que correspondem dois ciclos do aparelho discursivo sobre o turismo no arquipélago: o ciclo da espera e o ciclo dos projetos. A primeira parte reporta-se aos anos de 1962-1967 e encontra-se balizada pelas visitas de Adriano Moreira em agosto de 1962 e de Francisco da Cunha Leão, Agente Geral do Ultramar, em dezembro de 1967. A segunda reporta-se ao período de 1968-1974, iniciado com a visita de Américo Tomás em fevereiro de 1968, e marcado pelo fim do salazarismo e pelos "dois andamentos" do marcelismo (Rosas 1998: 486).

\section{Saber esperar (1962-1967)}

\subsection{Sem saber por onde começar}

O primeiro artigo sobre turismo foi publicado no dia 27/9/1962 intitulando-se, como muitos dos que lhe sucederam, "Turismo em Cabo Verde" e iniciava a série da seguinte forma:

"Conhecedores de todas as ilhas do arquipélago, com maior ou menor permanência em cada uma, ocorreu-nos a ideia de trazer ao conhecimento dos que nos lêem dentro e fora destas ilhas, a descrição das belezas que possui e tão pouco conhecidas são. (...) Confessamos que nos sentimos indecisos, sem saber por onde começar".

O propósito deste artigo é comum à maioria dos textos publicados neste período, visando publicitar as potencialidades turísticas do arquipélago e, em muitos casos, a capacidade do turismo de atrair capital, fomentar emprego e elevar o nível de vida das populações. Procurando desconstruir a imagem de aridez associada ao arquipélago, estes textos exaltaram a sua diversidade paisagística que combinava os verdejantes vales de Santiago, Brava e Santo Antão com a beleza das praias da Boa Vista e do Sal, bem como a transparência do mar e a abundância de peixe e de crustáceos que poderia atrair praticantes de pesca desportiva e de caça submarina. A par da constante menção à proximidade à Europa, os predicados mais enaltecidos foram o clima e a morabeza ${ }^{6}$ dos seus habitantes, sublinhando-se continuamente a reduzida amplitude térmica anual, o grande número de dias sem chuva e a hospitalidade da população:

\footnotetext{
"Outro cartaz admirável para atrair o turista a Cabo Verde, e talvez este seja o primeiro, é o seu hospitaleiro e bom povo, bem educado e com elevado grau de cultura, que capricha em receber os seus hóspedes com lhaneza e superior correç̧ão. A gente de Cabo Verde usa de tais requintes na maneira de receber, que deixa o visitante verdadeiramente encantado. Mesmo nas casas mais modestas pode não haver uma cadeira para a visita, mas há gentilezas tais, que esta se sente bem com a maneira como é acolhida, esquecendo facilmente as deficiências materiais. Logo que o hóspede transpõe o limiar da porta ouve a doce frase cabo-verdiana: - «Queira ter a bondade de se sentar»!". ${ }^{7}$
} 
Ainda que este tópico seja adiante retomado, sublinho desde já que a construção da morabeza como cartaz turístico se insere na matriz discursiva luso-tropicalista, fazendo-a derivar do "modo português de estar no mundo". Note-se que mesmo em parágrafos sumários com informações práticas compiladas para turistas, é dito: "População: Hospitaleira e amável. Nenhuma espécie de descriminação racial. Perfeita harmonia na convivência entre brancos, pretos e mestiços, nos diversos escalões sociais". 8

A campanha de promoção turística realizada pelo semanário surge por vezes justificada como um imperativo derivado do desconhecimento e das dificuldades na obtenção de informações sobre o arquipélago. Sobre estas dificuldades chega a ser relatado que as Casas de Portugal, responsáveis pela promoção turística do país no estrangeiro, desaconselhariam viagens a Cabo Verde por falta de informação. Atente-se no seguinte artigo de José de Freitas, previamente publicado no Diário Popular:

"[O] Dr Mackay conta-me (...) suas andanças para desembarcar na Praia. Foi à Casa de Portugal em Londres. Em lugar de lhe responderem, perguntaram-lhe: «Cabo Verde, que quer o senhor lá ir fazer?» Ao que parece não acreditaram muito nos desejos de turismo do inglês. E mais nada adiantaram. Mackay escreve para o S.N.I. - e o S.N.I. não responde à sua carta - ou muito tardiamente responde. Estas contrariedades servem apenas para aumentar ainda mais o seu desejo de visitar o arquipélago. Faz as malas e embarca com sua mulher para Lisboa, na certeza de que a sua vontade pode remover montanhas. Instala-se no Estoril e todos os dias, durante mais de uma semana, calcorreia as ruas e avenidas da capital. Vai ao Secretariado, vai à Polícia. E todos ficam surpresos. «Turismo, em Cabo Verde? Que singular mania, a deste casal inglês». Todavia, eles irradiavam simpatia e averiguada a verdade do objectivo, receberam as autorizações de partida. Embarcou-se o casal no [navio] «Alfredo da Silva» - faz que anda, mas não anda...”.9

Os artigos publicados neste período não se reduzem, porém, à exaltação dos predicados turísticos cabo-verdianos. Muitos inseriram-se no noticiário da agenda do governo da província, destacando-se as notícias sobre a participação de Bento Levy na reunião dos directores dos C.I.T. e no Congresso Nacional de Turismo, ambos realizados em Lisboa em outubro de 1964. Nestas notícias foram transcritos excertos dos discursos proferidos, designadamente, pelo Ministro do Ultramar que terá afirmado ser o turismo "um meio natural de dar a conhecer aos estrangeiros que nos visitam a nossa maneira de estar no Mundo, o portuguesismo das nossas populações ultramarinas, os seus sentimentos de fidelidade a Portugal". ${ }^{10}$ Saliento ainda as notícias relativas à participação de Bento Levy no "II Congresso Nacional de Turismo" realizado em outubro de 1966 em Lourenço Marques e ao I Intercâmbio para o Turismo organizado pelo C.I.T. local a 20/5/1967 para assinalar, embora com um mês de atraso, o dia do turista. Este intercâmbio consistiu numa visita à ilha de Santiago oferecida a um pequeno grupo da elite mindelense e salense, compreendendo uma excursão em autocarro panorâmico, que incluiu, como vinha já sendo hábito, uma visita à Cidade Velha e à exploração agrícola do Eng. ${ }^{0}$ Almeida Henriques em Santa Cruz. ${ }^{11}$

\subsection{Construir com vagar e persistência}

Em muitos destes artigos, registaram-se queixas sobre a falta de infraestruturas, sobretudo ao nível dos transportes e do alojamento que inviabilizariam o desenvolvimento do setor. De acordo com um texto publicado em meados de 1965, as ligações ao exterior por via marítima eram asseguradas por barcos da carreira da Guiné que sairiam de Lisboa duas vezes por mês, chegando a Cabo Verde cerca de uma semana depois ${ }^{12}$. A 5/11/1964, o jornal noticia, na primeira página, que os TAP da carreira da Guiné tinham começado a escalar Cabo Verde "abr[indo] melhores e maiores horizontes à política de aproximação e unificação do todo Nacional, ligando os elos desta corrente que nos torna uno e indivisíveis". O primeiro voo semanal chegava ao Sal na madrugada desse dia, com 24 horas de atraso. Em 1965, José de Freitas descrevia as suas dificuldades em obter uma reserva na TAP: "para obter um lugar até ao Sal, no avião da carreira da Guiné houve que mexer o céu e a terra. Bem apadrinhado, lá consegui a garantia do lugar. Uma autêntica lança em África”. ${ }^{13}$

O turista que conseguisse vencer os obstáculos das ligações externas e chegar de avião ao Sal onde se localizava o único aeroporto internacional existente -, ou de barco a S. Vicente ou a Santiago, confrontava-se com uma nova barreira: a insuficiência das ligações internas. Num texto de 1963, Júlio Vera-Cruz relatava que "partiram de França, com destino a esta ilha [S. Vicente], quatro ou cinco caçadores submarinos franceses, que tiveram de ficar no Sal cerca de 20 dias, não tendo chegado a vir a S. Vicente por falta de transporte...". ${ }^{14}$ Também José de Freitas no artigo supracitado relata que as ligações internas eram asseguradas por um navio que aparecia num porto a cada "dez ou mais dias", uma vez que os aviões dos TACV ${ }^{15}$ que asseguravam o transporte de passageiros entre algumas ilhas se "finaram todos de morte natural", interrogando: "[p]ode assim, honestamente, tentar-se turismo?". 
A estes problemas juntavam-se ainda o péssimo estado das estradas, o deficiente abastecimento de água e de eletricidade ou a insuficiência de unidades de alojamento. Sobre este último tópico, recorro de novo ao artigo de Júlio Vera-Cruz que denunciava ser "extraordinariamente difícil" conseguir reservar cinco quartos em S. Vicente. No mês seguinte, a 11/7/1963, era anunciada na primeira página do jornal a constituição de uma empresa na ilha de S. Vicente que projectava construir um hotel "com capacidade inicial de 70 quartos e susceptível de ser ampliada para 120" que viria a ser o Hotel Porto Grande, ainda em funcionamento no Mindelo.

Em 1966, o C.I.T. reuniu um conjunto de informações "úteis" sobre a ilha de Santiago e de S. Vicente com dados sobre alojamento e transportes, publicadas, respetivamente a 17/2/1966 e a 3/3/1966. De acordo com estas informações, em Santiago, existiriam três pensões (Moreira, Paraíso e Serginho) localizadas na Praia e a Pousada Praia-Mar situada a dois quilómetros da cidade. Em S. Vicente existiriam também três pensões (Chave d'Ouro, Atlântida e Rialto) no Mindelo e uma pousada na Baía das Gatas que estava encerrada. Não há qualquer indicação sobre o número de quartos disponível em cada um destes estabelecimentos, não existindo igualmente informação sobre unidades de alojamento em outras ilhas, com exceção do "velho barracão" que servia de hotel no aeroporto do Sal. ${ }^{16}$ Com o título "Cabo Verde. Atracção desconhecida para os portugueses", foi publicado a 19/1/1967 um resumo do relatório apresentado por Bento Levy no "II Congresso Nacional de Turismo" indicando que o C.I.T. havia proposto a construção de pequenas pousadas em Santa Catarina, Tarrafal, Fogo e Santo Antão.

Alguns dos textos publicados neste período fazem suceder ao relato dos obstáculos elencados, um discurso assente nas cautelas que deveriam ser tomadas na promoção do turismo. Atente-se nas palavras de Bento Levy na Assembleia Nacional, no fim de 1964:

\footnotetext{
“[E]stou perante realidades, e não corro atrás de quimeras e utopias. Como é que se há-de incrementar o turismo em Cabo Verde, perante as perspectivas que desbobinei, sem dramatizar, limitando-me a relatar factos? (...) Como promover a ida de turistas a S. Vicente, sem comunicações certas, rápidas e pouco espaçadas no tempo (...) sem hotéis, sem água, sem esgotos? Como levar turistas a Santiago (...) se, ao fim e ao cabo, os teremos enclausurados, sem poderem sair, quer pelo ar, quer pelo mar? Como aproveitar as estupendas condições de Santo Antão, de vales profundos e verdejantes, numa paisagem paradisíaca, sem estradas para percorrer a ilha e arriscando o turista à clausura ou a ter de atravessar o canal encapelado que separa Santo Antão de S. Vicente em barcaças para transporte de água, sem o mínimo conforto? Como Sr. Presidente? Como?

Não, meus senhores! Não basta dizer que temos durante seis a oito meses do ano um clima óptimo, lindas praias, paisagens de sonho, ao lado de outras de estarrecer, um folclore cheio de colorido e de interesse, um convívio racial que é exemplo para o Mundo. É preciso criar condições próprias para explorar tudo isso. Esta a razão por que me bato pelas infra-estruturas. Fazendo-o, preparo o futuro do turismo em Cabo Verde, que presentemente apenas pode dar os seus primeiros vagidos. Seria perigoso teimar agora, pela péssima propaganda que daí resultaria para esse futuro, que temos de construir com vagar e persistência que esperemos não seja infinita."17
}

Em fevereiro de 1967, a derrota do suposto combate pelas infraestruturas deu lugar a uma nova narrativa:

\begin{abstract}
"Toda a gente fala em turismo. Anda por aí uma autêntica euforia. (...) não podemos entusiasmar-nos em excesso, para aplicação de avultados dinheiros públicos numa indústria que dá agora os primeiros passos, sem sabermos, com relativa segurança, qual o melhor encaminhamento a imprimir-lhe. (...) A posição do Estado tem de ser de atenta expectativa, facilitando iniciativas, para depois actuar (...). Com efeito, não se vai impor, mas deixar escolher as ilhas que melhor possam servir o turismo com as suas características especiais que se pretende explorar. (...) Para apoiar o turismo em Cabo Verde, o Estado não pode começar a abrir estradas, construir cais acostáveis, aeroportos, pousadas, etc. em todas as ilhas. (...) Esperemos, pois, as preferências, a concretização dos planos e sua evolução. Só então será lícito que o Estado aplique réditos no fomento específico do turismo". ${ }^{18}$
\end{abstract}

\title{
1.3. Os primeiros vagidos: a chegada de turistas e de capitalistas encantados
}

Apesar dos condicionalismos descritos, os turistas foram chegando a Cabo Verde, desde logo em cruzeiros que escalavam os portos do Mindelo ${ }^{19}$ e da Praia. Ao longo de todo o período, a chegada de turistas a Santiago foi sempre mais destacada, o que pode derivar da localização do jornal nesta ilha ou do facto de a presença de estrangeiros em S. Vicente não constituir novidade (cf. Correia e Silva 2005). 
Sobre a chegada de cruzeiros à Praia, foi amplamente anunciada a vinda de um navio russo com 300 turistas escandinavos no dia 30/12/1966:

"Tratando-se de tão avultado número de visitantes que, pela primeira vez, visitam esta cidade e esta ilha o facto está causando um estado de espírito de prazer e atenta expectativa em cada habitante. De prazer por que todos desejam pôr esta magnífica ilha de Santiago integrada no roteiro das grandes excursões turísticas e, mais do que isso, todos querem que ela, em si mesma, seja uma ilha turística. De expectativa porque sendo tantos, perante tão poucos recursos, se não concebe como tudo possa ser organizado, sabendo-se que os turistas querem visitar a Cidade Velha, Trindade, o Curralinho, S. Jorge dos Órgãos, Santa Catarina, Santa Cruz e praias, muitas praias". ${ }^{20}$

A 5/1/1967 referia-se que o navio transportava apenas 254 turistas e que cerca de 100 não desembarcaram dada a sua idade avançada e a inexistência de cais acostável. Era ainda afirmado que teriam partido "todos encantados. E nós encantados ficámos porque, ao fim e ao cabo, o dia 30 de Dezembro de 1966 pode ter sido o primeiro de muitos outros dias de «Turistas em Santiago»."

Foi também noticiada a estada do casal Mackay nos primeiros meses de $1965,{ }^{22}$ de uma suíça em $1966^{23}$ e de 71 suecos que chegaram de avião ao Sal em maio do mesmo ano, tendo sido depois transportados para Santiago em voos sucessivos num avião dos Transportes Aéreos da Guiné que terá avariado durante uma das operações. Este grupo, liderado por Berl Gutenberg, terá permanecido sete dias em Cabo Verde, tendo visitado apenas as ilhas do Sal e de Santiago, onde ficou hospedado na Pousada Praia-Mar, na Pensão Paraíso e na Estalagem Sol-Mar, aberta especialmente para o efeito. O semanário considerou este "número de turistas bastante elevado para as condições do meio"24, referindo na edição de 12/5/1966:

"a cidade e toda a ilha sofreram um pequeno abalo na pacatez do seu viver. Correrias permanentes de táxis e pequenos autocarros atormentaram os peões e pelas estradas, de manhã até à tarde, nuvens de poeira assinalavam a passagem dos veículos conduzindo os forasteiros para a Cidade Velha, Tarrafal, Curralinho, S. Jorge, Praia Baixo e S. Francisco. Muita improvisação? Sem dúvida. Mas estas arrancadas são necessárias. Sem coragem nada se consegue. Ainda que sem as infra-estruturas indispensáveis, era preciso começar e começou-se mesmo. Organização defeituosa, na medida em que se não atendeu aos condicionalismos locais, ela tinha que pecar por excessos. (...) Mas, se fôssemos mais devagar, com os pés mais fincados no chão? É preciso não estancar uma fonte de benefícios contínuos". ${ }^{25}$

Muitos destes artigos possuem alguns parágrafos escritos num tom pedagógico e por vezes ameaçador, dando orientações de comportamento à população ou ao comércio. No artigo supracitado de 12/5/1966 lê-se que "é dever do comércio colaborar, abastecendo-se melhor" com "discos com música cabo-verdiana e postais - muitos postais - pequenas lembranças do nosso incipiente artesanato". Os avisos à população foram proferidos, por exemplo, a propósito da chegada do cruzeiro com turistas escandinavos, incitando a população a colaborar "com o seu civismo, evitando aglomerações e atitudes que contrariem o conceito formado de povo civilizado, educado e acolhedor que habita estas ilhas" ${ }^{26}$ Contudo, estes conselhos atingem novos contornos num artigo publicado na semana seguinte:

"é indispensável evitar que se caceteie, (engoli o termo) o turista. É necessário evitar que essa garotada - que só aparece quando não é preciso - e os exibicionistas de malezas importunem e alterem a vida da ilha. (...) O assédio ao turista repugna-o e não é isso que se pretende, nem é assim que o atrairemos. Já agora cautela senhores amadores da coisa alheia! Vejam lá não se «enganem» com o que levam ou com o que ficam. $\mathrm{O}$ turista também detesta esses enganos... A Polícia está alerta, vocês acabam por ir parar à cadeia (...) Juizinho, portanto. Sejam correctos e... não macem” ${ }^{27}$

Sendo quase nulas as menções a turistas portugueses, em julho de 1966, lamentava-se a sua ausência e alertava-se para a necessidade de "criar uma corrente nacional de turistas". ${ }^{28}$ Em agosto do mesmo ano, a propósito da chegada a S. Vicente do cruzeiro organizado pela F.N.A.T. com destino a Luanda, escrevia-se: "até que enfim vimos turistas portugueses em Portugal". ${ }^{29}$

Entre as notícias sobre estrangeiros que chegavam a Cabo Verde, encontramos uma série de artigos sobre a chegada de potenciais investidores, por vezes apelidados elogiosamente de "capitalistas", intensificada em 1966 e 1967. São eles os belgas Vynckier, o sueco Berl Gutenberg, interessado na ilha de Santiago ${ }^{30}$, o austríaco Benjamin Ehrlich, Presidente do Conselho da Câmara de Comércio da 
Argentina em Portugal ${ }^{31}$ e o alemão Rul Bückle (diretor da Südflug e da Atlantic Interplan) que vem recomendado por Ehrlich, mostrando-se interessado na instalação de um complexo turístico na Boa Vista.

Pela importância que tiveram e por terem sido os únicos que realizaram obra neste período, detenho-me nos Vynckier. Embora existam várias notícias nos anos de 1965-1967 sobre a sua chegada ao Sal é uma notícia de 27/4/1967, intitulada "A ilha do Sal em foco", que melhor relata a história deste casal belga. Procurando um local com bom clima por razões de saúde, terão chegado pela primeira vez ao arquipélago, de acordo com este texto, em "Janeiro de 1964". Em 1966, instalam um pequeno alambique solar em Santa Maria (Sal) que, através de destilação de água do mar fornecia "3 a 5 metros cúbicos de água doce por dia" e montam a "moradia-pousada" pré-fabricada que apelidaram de Morabeza. $\mathrm{Na}$ edição de 9/11/1967 lê-se que os Vynckier pretendiam construir "um hotel, piscinas, um casino, cinema, teatro e uma instalação dessalinizadora para produzir cerca de $500 \mathrm{~ms}$ de água potável por dia". ${ }^{32}$ Em vários destes artigos, é produzido um largo elogio ao clima e à invulgar transparência do mar de Santa Maria, afirmando-se que a vila terá "diante de si um futuro turístico que pode torná-la, em poucos anos, rival séria das ilhas Canárias, onde o afluxo de turistas está em constante progressão e onde a construção de hotéis se processa em ritmo vertiginoso". ${ }^{33}$

No final de 1967, os dados tinham já sido lançados e estavam escolhidas as ilhas para albergar o grande projeto de transformar Cabo Verde num destino alternativo às Canárias. Em dezembro de 1967, noticiava-se: "[d]ado o interesse que as possibilidades turísticas de Cabo Verde vem despertando em todo o mundo e a necessidade de se realizar um planeamento do turismo devidamente estruturado, o Ministério do Ultramar resolveu mandar ao arquipélago" Ruy Heitor (dos Serviços de Relações Públicas e Turismo da A.G.U.) e Manuel Rocha (Director do Gabinete de Estudos e Planeamento do Comissariado de Turismo $)^{34}$, aos quais se juntou, nove dias depois, a 15 de dezembro, o próprio Agente Geral do Ultramar, Francisco da Cunha Leão. Após visitarem as ilhas eleitas pelos investidores, terão regressado a Lisboa "convencidos das condições turísticas de Cabo Verde" ${ }^{35}$ Num texto publicado a 14/12/1967, Ruy Heitor avisava que o grande interesse dos estrangeiros por Cabo Verde deve ser "convenientemente acompanhado e orientado" para evitar "graves erros urbanísticos que se verificam em tantos locais", acrescentando que "a assistência técnica que os Serviços de Turismo da Agência Geral do Ultramar terão todo o prazer em prestar aos Serviços Provinciais de Cabo Verde, poderá contribuir poderosamente para uma melhor coordenação de esforços e iniciativas". ${ }^{36}$

\section{Desenhar com tintas fortes (1968-1974)}

\subsection{Na sã convivência de um escândalo meteorológico}

Neste período, a proliferação de artigos sobre os projetos para as ilhas do Sal, Boa Vista e Maio reforçou a imagem turística do arquipélago como destino de sol e praia, continuando a sua propaganda a sustentar-se nos mesmos dois ingredientes: o clima e a morabeza. No que concerne ao clima, deve ser notado que a sua glorificação foi amplificada apesar de se atravessar um novo ciclo de seca, de uma parte da população ter experienciado as trágicas fomes dos anos de 1940 e da estiagem e subsequentes crises alimentares terem constituído um elemento basilar na construção da cabo-verdianidade empreendida durante o Estado Novo. ${ }^{37}$ Em 1972, um ano de seca extrema em que se discutiam as possibilidades técnicas de provocar chuva artificial no arquipélago, Mário de Oliveira escrevia que o clima de Cabo Verde "é dos melhores do mundo, se não o melhor no dizer dos especialistas, e com a vantagem de poder receber turismo durante os doze meses do ano, um autêntico "escândalo meteorológico»" ${ }^{38}$ No mesmo ano, escrevia-se ainda:

"A seca de cinco anos - flagelo sócio-económico que preocupa as populações locais e já obrigou o Governo de Lisboa a medidas de emergência - será a riqueza que explorada no capítulo turístico se revelará manancial inesgotável. Aqueles que hoje lamentam cinco anos sem chuva, hão-de desejar que se prolongue o tempo seco quando houver turismo em quantidade suficiente para tornar rentável o que hoje só representa desastre económico". ${ }^{39}$

Se a estiagem passou a ser descrita como o grande atrativo turístico do arquipélago, o turismo passou a ser encarado como a mágica solução para os seus problemas. Ao longo deste período multiplicam-se os aplausos ao governo no combate à crise provocada pela seca. Neste ponto, saliento os artigos de Händel de Oliveira, então jornalista do Diário de Notícias, intitulados "Vitória contra a seca" e publicados em O Arquipélago em finais de 1972 e inícios de 1973. No primeiro destes textos lê-se na nota introdutória: 
“Toda a gente sabe que Cabo Verde está a sofrer uma das maiores secas da sua história e que, por tal motivo, ascendem já a cerca de vinte mil os cabo-verdianos que vieram para a Metrópole em busca de trabalho. Toda a gente sabe também que (...) ninguém no Arquipélago morreu de fome ou por falta de assistência médica - facto que, justificadamente, é motivo de orgulho para os responsáveis pelos destinos da Província”.

No mesmo artigo, o jornalista afirmava que os cabo-verdianos

"têm um ar saudável e alegre e o ambiente geral, por muito paradoxal que pareça, é de prosperidade. Por todo o lado se encontram em curso melhoramentos públicos - abrem-se estradas, alargam-se aeroportos, constroem-se escolas, hospitais e outros edifícios; aumenta-se a rede eléctrica, apetrecham-se os portos marítimos, modernizam-se comunicações; fala-se no aparecimento de indústrias e são constantes, quase diárias, as visitas de estrangeiros interessados na exploração de empreendimentos turísticos". ${ }^{40}$

No que respeita à morabeza, o seu elogio não se circunscreveu apenas aos artigos sobre turismo, constituindo uma matriz discursiva aliada à retórica de negação do colonialismo e da guerra e aplicada aos mais variados temas. Atente-se na seguinte frase de uma notícia sobre a visita de Américo Tomás a Cabo Verde em fevereiro de 1968: "Respira-se paz em todos os lugares, há um sorriso aberto de boas-vindas em todos os olhos, um capricho de galhardia de bem receber". ${ }^{41}$ Veja-se ainda que as alusões à morabeza e ao turismo integraram grande parte da narrativa sobre a espinhosa missão de "mostrar ao mundo" a proclamada "sã convivência" e a ausência de racismo nas províncias ultramarinas. O jornal chegou mesmo a esclarecer que o turismo, apelidado de "indústria da Paz", "comporta considerações de ordem política, por ser hoje dos mais importantes e mais sólidos meios de informação" ${ }^{42}$ ou ainda que:

"Sentido quanto a nossa África anda mal conhecida - ou mesmo compreendida - dos europeus, torna-se inexcedível a solicitude dos cabo-verdianos, em esclarecer particularmente os turistas, franqueando-lhes com alegria e generosidade, todos os recantos da sua terra". ${ }^{43}$

Tal como no período anterior, também nesta fase muitos dos artigos relativos ao noticiário da agenda governamental da província remetem para o turismo, de entre as quais realço os referentes às reuniões dos diretores dos C.I.T. em 1971 e $1973,{ }^{44}$ à atribuição de bolsas de estudo de hotelaria ${ }^{45}$ e à realização em 1968 e 1969 do II e III intercâmbios para o turismo, dedicados respetivamente ao golfe e à pesca desportiva. ${ }^{46}$

\subsection{Turistas, transportes e alojamento}

Neste período, verifica-se uma quebra no peso de artigos sobre a chegada de turistas e de investidores que poderá decorrer da intensificação da sua frequência. ${ }^{47}$ De entre os artigos referentes a este tópico, destaco os que se reportam à chegada de cruzeiros às cidades de Mindelo (entre 1968-197048 e em 1974) e da Praia (nos anos de 1971-1973), bem como três artigos assinados por Andrée Savoie sobre as suas férias no arquipélago, publicados em Dezembro de $1968^{49}$, com informações práticas compiladas com o objetivo de auxiliarem turistas franceses que pretendessem visitar Cabo Verde.

A marca ideológica e moralista do jornal surpreende-se também no discurso sobre os turistas, como se pode verificar numa notícia de 8/1/1970, com o título "Um iate carregado de "hippies» fundeou na Praia", que caracterizava os onze passageiros como um "espectacular grupo de "guedelhudos» (...) que honrando a tradição do seu "clan", se apresentaram, como é de rigor, sujos, descalços uns, longa ganforina todos, exóticos até ao fim" e "com pouco culto pela higiene". Tentando explicar aos leitores "como é que esta tão burguesa cidade caiu na rota da embarcação carregadinha de gente estranha", o articulista anónimo revelava que o grupo considerava "Cabo Verde melhor do que as Canárias" por estarem estas últimas ilhas "superlotadas de turistas, tornando-se incómodas".

No que tange ao tema do problema dos transportes e alojamento, começo por referir alguns progressos nos transportes aéreos sobretudo no que concerne às ligações internas. De acordo com o director dos TACV - numa entrevista cedida em julho de 1971 à Emissora Nacional -, em 1968, três bimotores Dove de nove lugares ligavam já as ilhas de Santiago, S. Vicente, Boa Vista, Sal e S. Nicolau. As ligações entre a Praia e as ilhas do Maio e do Fogo eram então asseguradas por dois pequenos monomotores Auster que operavam em regime de fretamento. $\mathrm{O}$ número de passageiros transportados pelos TACV que, em 1968, atingira os 11.535, havia aumentado para 17.596 em 1970 e só no primeiro semestre de 1971 a empresa havia registado 10.494 passageiros. Face a este aumento e sendo a frota 
dos TACV em meados de 1971 a mesma de 1968, requeriam-se dois aviões com maior capacidade do que os Dove e um "bimotor ligeiro de tipo Islander" para ligar a Praia às ilhas do Fogo e do Maio que viria a iniciar voos regulares logo em novembro de $1971 . .^{50}$

Sobre as ligações marítimas entre ilhas, é mencionado num artigo de 1971 que estas seriam asseguradas por pequenas e obsoletas embarcações a motor, existindo uma única "embarcação maior que circula duas vezes por mês, ora num sentido, ora noutro, o que equivale a ligações de mês a mês". ${ }^{51}$ Também no que tange às ligações com o exterior, marítimas ou aéreas, o discurso foi ao longo deste período de desalento, salientando-se continuamente as dificuldades em conseguir-se uma reserva.

A oferta de alojamento, malgrado o seu crescimento, continuou a constituir um entrave ao desenvolvimento do turismo. No início de 1973, Händel de Oliveira dá-nos conta que na cidade da Praia continuariam a existir apenas a Pousada Praia-Mar e três pensões que, no total, somavam 58 quartos. No Mindelo, a par das pensões já existentes no período anterior, havia agora o Hotel Porto Grande com 52 quartos, "metade dos quais, porém, não estão ainda mobilados". ${ }^{52}$ Nas restantes ilhas, e ainda de acordo com o mesmo jornalista, existiria uma pousada municipal na Brava com oito quartos e uma outra no Fogo com quatro quartos "instalada provisoriamente, sem nenhumas condições, numa casa particular". Aguardava-se ainda a conclusão da nova pousada do Fogo com 26 quartos e projetava-se a construção de uma pousada em Santo Antão e de outra em S. Nicolau. No Sal, a par do "antiquíssimo hotel" do aeroporto, existiria uma "estalagem de luxo na vila de Santa Maria", propriedade dos Vynckier, com "cinco quartos, que é complementada com anexos constituídos por uma série de pequenos apartamentos" ${ }^{53}$ que se enchiam apenas com a tripulação dos aviões da South African Airways que faziam escala no Sal. Na tentativa de estimular o turismo interno, o C.I.T. havia iniciado a construção de uma aldeia turística na vila do Tarrafal com um parque de campismo e "alguns «bungallows»".

Com o propósito de ilustrar de forma mais explícita a evolução da oferta de alojamento, recorro à informação disponível nos anuários estatísticos do ultramar para os anos de 1964-1973, sintetizada na tabela 1.

Tabela 1: Evolução do número de unidades de alojamento e de quartos em Cabo Verde

\begin{tabular}{|l|c|c|c|c|c|c|c|c|c|c|}
\hline & $\mathbf{1 9 6 4}$ & $\mathbf{1 9 6 5}$ & $\mathbf{1 9 6 6}$ & $\mathbf{1 9 6 7}$ & $\mathbf{1 9 6 8}$ & $\mathbf{1 9 6 9}$ & $\mathbf{1 9 7 0}$ & $\mathbf{1 9 7 1}$ & $\mathbf{1 9 7 2}$ & $\mathbf{1 9 7 3}$ \\
\hline $\begin{array}{l}\text { Unidades de } \\
\text { Alojamento }\end{array}$ & 9 & 8 & 10 & 8 & 8 & 10 & 9 & 13 & 14 & 14 \\
\hline Quartos & 85 & 89 & 106 & 101 & 118 & 181 & 148 & 187 & 211 & 218 \\
\hline
\end{tabular}

Fonte: Anuário Estatístico do Ultramar (1965-1973)

Note-se que a grande maioria destas unidades eram pensões e que, no fim deste período, de entre as sete províncias ultramarinas, Cabo Verde ocupava o quarto lugar em termos de oferta de alojamento, ficando, todavia, muito aquém de Macau, de Moçambique e de Angola que, em 1973, dispunha de 6263 quartos em 362 estabelecimentos hoteleiros.

\subsection{Desenhar com tintas fortes}

Ao longo deste período multiplicam-se as referências aos grandes projetos da Detosal, Atlântico-Interplano e Turmaio, sociedades constituídas para o desenvolvimento turístico das ilhas do Sal, Boa Vista e Maio. O entusiasmo em torno destes projetos deixa-se apreender na forma como o futuro de Cabo Verde passa a ser antevisto como o "mais concorrido e famoso centro de atraç̧ão turística de todo o espaço português". ${ }^{54}$

O projeto para a ilha do Sal circunscrevia-se à vila de Santa Maria e partiu da iniciativa da já referida família Vynckier. Em maio de 1968, Eduardo Soares, enviado especial do Jornal de Notícias revelava que o casal belga havia já mandado elaborar um projeto que compreendia "um hotel com cem quartos, piscinas de água do mar (fria e quente), solários, "courts» de ténis, etc" e encontrado o slogan para publicitá-lo: "Visite Cabo Verde - O verdadeiro paraíso na terra: SOL, PRAIAS E CRIOULAS". 55 Em 1970, foi assinada a escritura de constituição de uma sociedade de economia mista denominada Detosal - Sociedade para o Desenvolvimento do Turismo da Ilha do Sal, SARL com "o capital social de 12 mil contos e dela faz parte o Governo da Província, pertencendo-lhe 7.200 das 12.000 acções". ${ }^{56}$ Em abril de 1971, o governador da província divulga numa entrevista que este projeto contemplava agora 
"cinema, boites" e que, numa fase posterior, seria erguido um hotel com 25 pisos $^{57}$. Em 1973, H. de Oliveira escreve que a Detosal possuía apenas a fase preliminar de um estudo que havia encomendado e que não tinha conhecimento da existência de uma política definida para o "aproveitamento da vasta área que lhe foi concedida" ${ }^{58}$ No pós-independência, os Vynckier continuaram a expandir a sua Pousada Morabeza em Santa Maria - cidade que hoje possui um busto de Georges Vynckier com uma placa onde se lê "pioneiro do turismo" e uma rua com o seu nome.

São também frequentes as referências ao grande projeto da Sociedade Atlântico-Interplano para Santa Mónica, na ilha da Boa Vista, que, tal como o anterior, se arrastaria até 1974 sem concretização. De acordo com uma notícia de 17/7/1969, este projeto compreendia vários hotéis, equipamentos desportivos e comerciais, um aeroporto, um porto marítimo e um casino e a sua primeira fase deveria "ser iniciada logo após a celebração do contrato de modo a estar concluída em 1972 " ${ }^{59}$ O contrato só viria a ser assinado dois anos depois, obrigando a Atântico-Interplano

"a construir, no prazo de dois anos, o mínimo de três hotéis com a capacidade de 1200 camas, procedendo entretanto à urbanização que se verifique ser necessária para o efeito. Igualmente se obriga, dentro do mesmo prazo, a construir um aeroporto na ilha da Boa Vista. O projecto total referente às áreas abrangidas pelo contrato deverá prever a existência de instalações hoteleiras com 6000 camas e a respectiva urbanização decorridos cinco a oito anos, a partir da assinatura do contrato". ${ }^{60}$

No mês seguinte, era anunciada a aquisição de " $30 \mathrm{~km}^{2}$ de terrenos" ao governo da província por parte da empresa que ficaria assim "em condições de iniciar os trabalhos de instalação do importante complexo turístico". ${ }^{61}$ Em outubro de 1972, o jornal informava que a empresa teria ainda de concretizar "uma imprescindível cláusula do contrato, respeitante à garantia bancária que assegure a execução dos empreendimentos". ${ }^{22}$ Note-se que só em 2011, quatro anos após a inauguração do aeroporto internacional da Boa Vista, abriu o primeiro resort no sul da ilha, próximo da praia de Santa Mónica, pertencente ao grupo RIU. ${ }^{63}$

A constituição da Turmaio - Sociedade de Turismo da Ilha do Maio - SARL, uma "sociedade inteiramente nacional", foi noticiada na primeira página da edição de 22/1/1970. ${ }^{64}$ De acordo com António de Azaredo, muitos dos sócios da Turmaio seriam "médicos que, conhecedores das boas condições locais para o tratamento de doenças alérgicas, doenças nervosas e certas doenças do colagénio, tencionam incluir clínicas médicas no complexo a construir" ${ }^{65}$ Em 1973, a Turmaio estaria ainda a elaborar "a minuta do contrato a celebrar" com o governo da província. ${ }^{66}$

Desconhecendo-se as razões que terão motivado as sucessivas prorrogações dos prazos previstos, o semanário responsabiliza estas sociedades. Em 1973 e 1974 são já escassas as referências a projetos turísticos. Com feito, a aceleração da inversão de marcha no processo liberalização ensaiado durante a primavera marcelista, a crise económica, a crise petrolífera de 1973, o apertar do cerco internacional, a proclamação da independência da Guiné-Bissau e a própria insustentabilidade do regime acabaram por diluir as tintas fortes com que se tinham anunciado estes projetos.

$\mathrm{O}$ discurso oficial do governo da província relativamente à gestão das propostas de empreendimentos turísticos foi pautado pelo alerta para o problema da especulação imobiliária. Atente-se nas palavras do governador:

"[U]m estrangeiro precisa de obter autorização para a aquisição de bens imóveis. Assim, os pedidos passaram a ser cuidadosamente apreciados e só virão a ser deferidos aqueles que forem considerados de interesse para a província, quer pela grandeza dos empreendimentos, quer em face da capacidade financeira e da idoneidade dos requerentes. (...) Devemos procurar, a todo o custo, evitar a repetição de erros cometidos noutros territórios e cujas consequências se mostram hoje irreversíveis. Para que mais concretamente se avalie da delicadeza do assunto, acrescentamos nós um exemplo: as Canárias. (...) [Nas Canárias] foram concedidas as facilidades na aquisição de terrenos e construção de empreendimentos turísticos por estrangeiros. Simplesmente, hoje, acontece que os terrenos atingem preços exorbitantes e muitos desses empreendimentos, sempre esgotados, embora, quase nenhum lucro dão à Espanha, porque os turistas que os enchem pagam todas as despesas no país da sua naturalidade antes de fazerem a viagem - passagens, comida, alojamentos, transportes, etc. Nas Canárias limitam-se a comprar «recuerdos» e pouco mais. Luta-se em Cabo Verde para evitar, ao máximo, situações como esta" ${ }^{67}$

A referência ao arquipélago das Canárias é constante ao longo de todo o período. A par da realização de visitas de estudo em busca de "soluções a adoptar no desenvolvimento de Cabo verde" em vários 
domínios, nomeadamente no turismo ${ }^{68}$, o arquipélago vizinho serviu de espelho no qual os jornalistas retocavam a imagem propagandística de Cabo Verde, enaltecendo o "melhor clima, melhor temperatura da água e do ar" e o maior sossego de Cabo Verde, descrevendo invariavelmente as Canárias como um destino "próximo da saturação". ${ }^{69}$

Este período, que defini como o ciclo dos projetos, encerra com o derradeiro projeto turístico do C.I.T. para Cabo Verde, concebido e anunciado após a revolução de abril de 1974. Cerca de um mês decorrido sobre a libertação dos presos políticos do campo de concentração do Tarrafal a 1 de maio de $1974^{70}$, o jornal publicava a seguinte notícia com o título "O Presídio do Tarrafal transformado numa estância turística":

"Por decisão do Encarregado do Governo, própria de um momento revolucionário que escolheu espontaneamente como símbolo uma flor, a vasta área do tristemente célebre Campo de Trabalho, mais conhecido por Presídio do Tarrafal, vai ser transformado numa estância turística, após um estudo prévio do C.I.T.. Serão aproveitados para o efeito, cerca de 20 «bungalows», fora da antiga prisão fortificada, que serviam de habitação ao pessoal que ali prestava serviço, além da magnífica casa do ex-director do estabelecimento prisional, rodeada de plantas e jardins, que vai ser transformada numa pousada. A Câmara Municipal do Tarrafal abrirá, brevemente, um concurso para a exploração turística da área, que abrangerá uma zona do aprazível Colonato de Chão Bom". ${ }^{71}$

Veja-se ainda um excerto do anúncio deste concurso publicado na última edição deste jornal:

"I. Pretende-se alugar, para exploração turística, a nível internacional, a zona do Tarrafal onde funcionou o conjunto prisional, já extinto.

II - A zona é formada por: a) Um complexo residencial composto de 6 blocos com um total de 18 moradias; b) Uma ampla casa, com 5 quartos de cama, sala de estar, sala de jantar e outros cómodos, toda mobilada, situada a meia encosta, dominando um vasto panorama, que servirá para uma pousada turística". ${ }^{72}$

\section{Notas finais}

A intensa campanha de promoção turística levada a cabo nas páginas de O Arquipélago deve ser compreendida à luz das profundas transformações verificadas em Portugal neste período marcado pela guerra colonial e pela reação às críticas internacionais que fez da retórica luso-tropicalista a sua principal arma de arremesso. De entre as transformações verificadas neste período, saliento ainda a abertura do país ao exterior e a detonação do turismo de sol e praia, resultante da inclusão de Portugal no processo de litoralização e mediterranização do turismo europeu. ${ }^{73}$ É neste novo cenário estabelecido pela intensificação do turismo no litoral sul da metrópole cujas receitas começavam a contribuir para contrabalançar as despesas crescentes da guerra colonial que se insere a promoção turística de Cabo Verde. Esta promoção tentou incluir a província neste mercado regional europeu, publicitando-a como um prolongamento do extremo sul da Europa, um sul melhorado, passível de exploração turística durante todo o ano ${ }^{74}$ e com atributos paradisíacos associados às ilhas tropicais (Sheller 2001, Picard 2011). Numa fase em que a "praia global" de que nos fala Orvar Löfgren (1999) se encontrava já bem sedimentada num conjunto de fantasias tropicais, o semanário promovia a suposta excepcionalidade da tropicalidade (Arnold 2000) insular cabo-verdiana: uma tropicalidade encenada não só como "autêntica" - feita de coqueiros, jovens crioulas e praias de água tépida azul-turquesa ainda não maculadas pelo turismo de massas - mas também como segura e relaxante porque "domesticada" pelo luso-tropicalismo.

Enquanto órgão de informação do Centro de Informação e Turismo, O Arquipélago espelhou a fusão institucional entre o turismo e a propaganda do regime que caracterizou todo o Estado Novo, primeiro no âmbito do Secretariado de Propaganda Nacional, depois no Secretariado Nacional de Informação, Cultura Popular e Turismo e, a partir de 1968, na Secretaria de Estado de Informação e Turismo. Apesar das alterações verificadas no turismo durante o Estado Novo que fazem contrastar o país interior e ruralista das pousadas, promovido pelo Secretariado, com o país dos grandes hotéis no litoral sul nas vésperas da revolução, as estratégias discursivas patentes no semanário denunciam paralelismos com as forjadas em décadas anteriores para promover a metrópole. Algumas destas afinidades poderão derivar do facto de grande parte dos artigos terem sido escritos por jornalistas da metrópole que terão replicado modelos narrativos pré-estabelecidos, exaltando os mesmos itens - o clima, a hospitalidade, a 
paz, as "belezas turísticas" - e listando os melhoramentos que deviam ser efetuados. Estas regularidades discursivas são também explícitas na forma como o C.I.T. de Cabo Verde promoveu o turismo interno, recorrendo à folclorização e ao projeto de criação de uma rede de pousadas.

Esta tradição discursiva estado-novista sobre o turismo como parte integrante da propaganda nacional ${ }^{75}$, com raízes na I República, foi neste período intensamente mobilizada na campanha contra as críticas internacionais ao regime, atribuídas ao "grande desconhecimento" dos estrangeiros sobre o país. Se o turismo por si só se adequava à retórica de negação do isolamento internacional, em Cabo Verde, mais do que em qualquer outra colónia africana, a sua promoção ajustava-se às narrativas de negação da guerra e de exaltação de um dos principais ingredientes do luso-tropicalismo: a miscigenação. Neste sentido, Cabo Verde foi construído como uma montra da nação luso-tropical, onde o mundo e, em especial os detratores do regime, deveriam ir contemplar o pretenso "clima de paz", de "harmonia racial" e de "civilidade cristã miscigenada" do ultramar português.

O discurso sobre o turismo em Cabo Verde ventilado em O Arquipélago é parte integrante da estrutura narrativa do próprio projeto tardo-colonial português e insere-se numa guerra ideológica, na qual os turistas europeus são descritos como uma extensão do exército português, mais precisamente como "soldados da batalha da informação (...) que em vez de custar dinheiro, rende divisas". ${ }^{76} \mathrm{~A}$ insustentabilidade dos pressupostos ideológicos que orientaram esta propaganda e as suas narrativas assentes no escamoteamento de uma realidade à vista de todos não deve assim ser descurada na determinação das causas que levaram a que o turismo continuasse a ser uma miragem em Cabo Verde nas vésperas da revolução de 1974. Foi necessário esperar até à viragem do século para que o número de turistas no país ultrapassasse a barreira dos 100.000, meta alcançada no ano 2000 (Ferreira 2008: 264) em que as Canárias receberam mais de 10 milhões de turistas estrangeiros. ${ }^{77}$ São, porém, abundantes as simetrias entre o projeto desenhado no fim do Estado Novo e o perfil do turismo atual definido pela prevalência do segmento de sol e praia, praticado nas ilhas do Sal e da Boa Vista em unidades de alojamento de grande dimensão destinadas a turistas europeus. Estas semelhanças são também detetáveis ao nível da promoção turística que, denunciando o seu berço luso-tropicalista, continua a suportar-se da categoria morabeza, ocultando os seus contornos enquanto dispositivo de "desarmamento"78 e de subjugação da população a europeus, sejam eles turistas ou empresários hoteleiros, apelidados por muitos cabo-verdianos de novos colonos.

\section{Bibliografia}

Arnold, D.

2000. "Illusory Riches": Representations of the Tropical World, 1840-1950". Singapore Journal of Tropical Geography, 21(1): 6-18.

Bernardo, E.

2015. Perceção dos Impactos do Turismo na Ilha da Boa Vista, Cabo Verde. Tese de doutoramento em Sociologia. Lisboa: ISCTE-IUL.

Brito-Semedo, M.

2006. A Construção da Identidade Nacional. Análise da Imprensa entre 1877 e 1975. Praia: IBNL. Cadavez, C.

2012. A Bem da Nação. As Representações Turísticas no Estado Novo entre 1933 e 1940. Tese de doutoramento em Estudos de Literatura e de Cultura. Lisboa: FL-UL.

Carey, M.

2011. "Inventing Caribbean Climates: How Science, Medicine, and Tourism Changed Tropical Weather from Deadly to Healthy". Osiris 26 (1): 129-141

CIT.

S.d. Relatório do Centro de Informação e Turismo da Província de Cabo Verde, 1967. Praia: CIT.

Correia e Silva. A.

2005. Nos Tempos do Porto Grande do Mindelo. Praia-Mindelo: CCP.

Ferreira, E.

2008. O Turismo Sustentável como Factor de Desenvolvimento das Pequenas Economias Insulares: o caso de Cabo Verde. Lisboa: EUL.

Fonseca, I.

2014. A Imprensa e o Império na África Portuguesa, 1842-1974. Tese de doutoramento em Sociologia. Lisboa: ICS. 
Garcia, J.

2011. Ideologia e Propaganda Colonial no Estado Novo: da Agência Geral das Colónias à Agência Geral do Ultramar. 1924 - 1974. Tese de doutoramento em História. Coimbra: FL-UC.

INE.

2018. Estatísticas do Turismo. 2017. Praia: INE.

Lobo, S.

2010. "Sun, Sand, Sea \& Bikini. Arquitectura e turismo: Portugal anos 60". Revista Crítica de Ciências Sociais 91: 91-106.

Löfgren, O.

1999. On Holiday. A History of Vacationing. Berkeley, LA, London: University of California Press.

Mariano, G.

1991. Cultura Caboverdiana - Ensaios. Lisboa: Vega.

Mariz, V.

2016. "The understanding of the touristic value of Portuguese overseas monuments: the case of Angola

(1959-1974)". Journal of Spatial and Organizational Dynamics, IV(2): 157-168.

Oliveira Barros, J.

1998. "Trilogia eventual do tempo proibido". Em J.L. Almada (org.). Mirabilis de Veias ao Sol. Praia, IPC: $253-258$.

Oliveira, J.

1998. A Imprensa Cabo-verdiana. 1820-1975. Macau: Fundação Macau.

Picard. D.

2011. Tourism, Magic and Modernity: Cultivating the Human Garden. New York, Oxford: Berghahn.

Pina, L.

2011. "Cabo Verde: expressões ibéricas de cultura política, morabeza e cordialidade”. Confluenze 3(2): 237-253.

Rosas, F. (coord.).

1998. "O Estado Novo". Em J. Mattoso (dir.). História de Portugal. Volume VII. Lisboa: Estampa.

Rovisco, E.

2017. "Da resistência africanista ao suvenir africano: artesanato, nação e fantasmagoria na ilha da Boa

Vista, Cabo Verde". Etnográfica 21(1): 5-26.

Sánchez. E.

2004. "Turismo, desarrollo e integración internacional de la España franquista”. EBHA Annual Conference.

Barcelona. www.ebha.org/ebha2004/papers/7C2.doc

Sheller, M.

2001, "Natural hedonism: The invention of Caribbean Islands as tropical playgrounds", Sandra Courtman

(ed.) The Society for Caribbean Studies Annual Conference Papers, $2<\mathrm{http} / / / c o m m u n i t y-l a n g u a g e s$. org.uk/SCS-Papers/olv2p7.pdf

Silva, M., Oliveira, S.

2013. "Paquetes do Império. O ‘Primeiro Cruzeiro de Férias às Colónias”. Em M. Silva (dir.), Castelos a

Bombordo. Etnografias de patrimónios africanos e memórias portuguesas. Etnográfica Press: 261-284.

Zytnicki. C. e H. Kazdaghli (dir.).

2009. Le Tourisme dans l'Empire Français. Politiques, Pratiques et Imaginaires (xixe - xxe siècle): Un

Outil de la Domination Coloniale ? Paris: Société française d'histoire d'outre-mer.

\section{Notas}

1 De acordo com José Luís Garcia, os C.I.T. foram criados nas províncias ultramarinas "pelo Decreto-Lei n. ${ }^{\circ} 42.194$, de 27 de Março de 1959, (...) e logo decidido pelo mesmo diploma o funcionamento dos de Angola, Moçambique e Estado da Índia, ficando ainda pela mesma providência legislativa o ministro da tutela apto a criar, quando entendesse adequado, instituições idênticas nas restantes possessões (Cabo Verde, Guiné, S. Tomé e Príncipe, Macau e Timor), facto que viria a acontecer a 7 de Dezembro de 1960, em cumprimento do disposto na Portaria n. ${ }^{\circ} 18.111$, daquela data" (2011: 168). Embora os C.I.T. dependessem dos Governos das Províncias, constituíam uma extensão da Agência Geral do Ultramar, foram por ela subsidiados e tiveram o propósito de "superintender, incentivar e promover todas as actividades relativas à informação e relações públicas, ao turismo, aos espectáculos e às formas de cultura popular". Cf. "Lei orgânica dos C.I.T.", O Arquipélago, 15/3/1973, p. 8. No relatório do C.I.T. de Cabo Verde respeitante ao ano de 1967 é referido que este organismo funcionava com apenas três funcionários: diretor, chefe de secção e aspirante (CIT, s.d.: 1). 
2 O nome do diretor do jornal só é indicado até à edição de 28/5/1970. No último número publicado é divulgado que este foi dirigido pelos sucessivos directores do CIT: Bento Levy, Joaquim Ribeiro, António de Azaredo e Tomás Benrós. Cf. "No fim do Caminho", O Arquipélago, 20/6/1974, p. 7. Sobre este assunto, ver ainda Oliveira 1998: 556.

3 O número 122 não foi contemplado na análise por se encontrar em falta nas séries consultadas na Hemeroteca Municipal de Lisboa e na Biblioteca Nacional de Portugal.

4 Note-se ainda que a maioria dos textos produzidos pela redação não identifica a sua autoria. Na ausência de ficha técnica, socorro-me do último editorial do jornal que indica como seus colaboradores: "João Modesto, Marques de Oliveira, Orlando Levy, António Lopes Moniz, Ramiro de Azevedo, João de Deus Lopes da Silva, Alberto Cipriano de Sousa e Fernando Bandeira Tristão". Cf. "No fim do Caminho", O Arquipélago, 20/6/1974, p. 7; ver também Oliveira 1998: 575-576.

5 Esta pesquisa inseriu-se num projeto de pós-doutoramento intitulado "Turismo e Identificação Nacional em Cabo Verde", financiado pela Fundação para a Ciência e a Tecnologia (SFRH/BPD/72387/2010) e supervisionado pelo Professor Pedro Prista Monteiro, a quem agradeço, bem como à Vera Marques Alves, a valiosa revisão deste texto.

6 Categoria basilar na construção da cabo-verdianidade, a palavra do crioulo cabo-verdiano morabeza - por vezes empregue no jornal - designa uma hospitalidade ou cordialidade mais fraterna e carinhosa, entendida como específica da população do arquipélago. Sobre este assunto ver, por exemplo, Mariano 1991, Pina 2011.

7 Minhoto, "Turismo em Cabo Verde. Devaneio e repouso", O Arquipélago, 25/6/1964, p. 1, 2, previamente publicado no Diário de Lisboa.

8 "Informações úteis sobre o arquipélago", O Arquipélago, 17/2/1966, p. 3.

9 No mesmo artigo relata-se que o casal Mackay desembarcou na Praia às cavalitas de praienses para não se molhar, dada a calema desse dia e a inexistência de cais acostável. Cf. Freitas, José de, "Um arquipélago sem rios", O Arquipélago, 6/5/1965, p. 1, 3. Ver também "Cabo Verde - o turismo e as infra-estruturas", 25/3/1965, p. 3: "quando [os turistas] pedem os esclarecimentos nas casas de Portugal, a resposta é sempre a mesma: Não temos elementos".

10 "Os directores dos C.I.T. foram recebidos pelo Ministro do Ultramar", O Arquipélago, 15/10/1964, p. 6. Ver ainda "Reunião dos directores dos C.I.T.”, 29/10/1964, p. 1, 4

11 "Intercâmbio para o turismo...", O Arquipélago, 4/5/1967, p. 1; "Realizou-se o $1^{\circ}$ Intercâmbio...", 25/5/1967, p. 1, 8 .

12 Freitas, José de, "Um arquipélago sem rios", O Arquipélago, 6/5/1965, p. 1, 3; "Informações úteis sobre o arquipélago ”, 17/2/1966, p. 3. Além dos navios da carreira da Guiné, o Anuário do Turismo do Ultramar de 1964, refere os da Companhia Colonial de Navegação com destino à América do Sul, bem como de companhias estrangeiras que escalariam o Mindelo (p. 13).

13 Freitas, José de, "Um arquipélago sem rios", O Arquipélago, 6/5/1965, p. 1, 3. O volume do Anuário do Turismo do Ultramar de 1964 refere ainda que o "Voo da Amizade (TAP-PANAIR)" que ligava Portugal ao Brasil faria escala no Sal (p. 13).

14 Vera-Cruz, Júlio,"Perspectivas do turismo em Cabo Verde", O Arquipélago, 6/6/1963, p. 2.

15 Transportes Aéreos de Cabo Verde, empresa criada em 1958 e circunscrita à circulação entre algumas ilhas do arquipélago.

16 Estes dados coincidem com os do Anuário do Turismo do Ultramar de 1966-1967 que também não referem o número de quartos existentes (p. 11-12). O volume anterior, de 1964, refere a existência de 26 quartos no Hotel Atlântico no Sal, 16 na Pensão Chave d'Ouro, 8 na Atlântida, 12 na Pensão Moreira e 9 na Pousada Praia-Mar (p. 18).

17 "Cabo Verde e os seus problemas...", O Arquipélago, 17/12/1964, p. 6, 8.

18 “Turismo anti-económico", O Arquipélago, 2/2/1967, p. 1.

19 “Turismo. Ouvindo Mr. Parry Allerton...", O Arquipélago, 9/4/1964, p. 1, 3.

20 "No fim do ano turistas escandinavos em Santiago...", O Arquipélago, 15/12/1966, p. 1.

21 "Turistas em Santiago", O Arquipélago, 5/1/1967, p. 1, 8.

22 "Cabo Verde e o turismo", O Arquipélago, 18/3/1965, p. 1, 6.

23 "Cabo Verde desperta a 'morabeza' de uma suíça”, O Arquipélago, 9/6/1966, p. 1, 6.

24 "Turismo em Santiago", O Arquipélago, 5/5/1966, p. 1, 6.

25 "Turistas em Santiago", O Arquipélago, 12/5/1966, p. 3.

26 "No fim do ano turistas escandinavos...", O Arquipélago, 15/12/1966, p. 1.

27 "Notas soltas", O Arquipélago, 22/12/1966, p. 8.

28 "Rodapé", O Arquipélago, 21/7/1966, p.6.

29 "Turistas Portugueses em Portugal”, O Arquipélago, 25/8/1966, p. 1. Ver também "O cruzeiro da M.P. a Cabo Verde", 8/9/1966, p. 1,3 .

30 "Cabo Verde e o Turismo", O Arquipélago, 9/12/1965, p. 3; "Santiago e o turismo", 31/3/1966, p. 1, 6.

31 "O turismo em Cabo Verde pode ser uma realidade”, O Arquipélago, 9/2/1967, p. 1, 3.

32 "Turismo em Cabo Verde", O Arquipélago, 9/11/1967, p. 8.

33 “Turismo em Cabo Verde...", O Arquipélago, 20/10/1966, p.1, 6.

34 "Perspectivas do Turismo em Cabo Verde", O Arquipélago, 7/12/1967, p. 8.

35 "Regressamos a Lisboa convencidos...", O Arquipélago, 21/12/1967, p. 1, 8.

36 "Turismo em Cabo Verde", O Arquipélago, 14/12/1967, p. 10.

37 Veja-se o peso do tema da estiagem e, consequentemente, da fome e da emigração na produção literária, nomeadamente os romances Os Flagelados do Vento Leste de Manuel Lopes (1959) e Famintos de Luís Romano (1962).

38 Oliveira, Mário de, "Ilha de Santiago - Um oásis para o turismo", O Arquipélago, 8/6/1972, p. 6. Sobre a reconfiguração das representações associadas aos climas tropicais operada pela ciência e pelo turismo, ver, por exemplo, Carey 2011.

39 "Um paraíso perdido", O Arquipélago, 19/10/1972, p. 8, 6.

40 Oliveira, H., "Cabo Verde: Vitória contra a seca-1", O Arquipélago, 30/11/1972, p. 1, 10.

41 Pereira, Tito, "Cabo Verde, oásis atlântico de paz e de simpatia", O Arquipélago, 7/3/1968, p.1.

42 "Turismo como factor de informação", O Arquipélago, 19/9/1968, p. 1.

43 "Perspectivas turísticas...", O Arquipélago, 23/1/1969, p. 8. O artigo consiste na transcrição de parte da palestra proferida por Aragão Pinto. Marcelo Caetano, no VI Congresso Internacional de Turismo Africano terá afirmado o mesmo em relação aos colonos em África. cf. "Ao serviço do turismo das terras portuguesas do ultramar", em Andrade, Ferreira de (ed.), Anuário do Turismo do Ultramar. 1959-1960. Lisboa, Olisipo: s. p.. 
44 Ver artigos publicados nos dias 8/7/1971, p.1; 22/7/1971, p. 1, 4 e 25/10/1973, p.3.

45 Ver, por exemplo, edições de 26/9/1968, p. 3 e de 27/9/1973, p. 4.

46 Ver edições de 5/12/1968, p.1 e 6 e de 4/9/1969, p. 1 e 10

47 Numa entrevista à Emissora Nacional, António de Azaredo afirma que "quase todas as semanas chegam visitantes estrangeiros isolados", 21/10/1971, p.3.

48 Num artigo de 1/6/1972, intitulado "Turismo em Cabo Verde: Realidades que se impõem", Teixeira de Sousa afirmou que "os barcos ingleses desistiram de escalar S. Vicente, onde topavam com uma série de dificuldades e incomodidades" (p. $5)$.

49 "Férias em Cabo Verde", 5/12/1968, p 1, 6, 8; 12/12/1968, p. 1, 4; 19/12/1968, p. 4.

50 "Problemas de Cabo Verde na Emissora Nacional", O Arquipélago, 18/11/1971, p.1, 2.

51 “A vida e a evolução de Cabo Verde...”, O Arquipélago, 26/8/1971, p. 3.

52 Em fevereiro de 1974 inaugurava-se no Mindelo a Pensão Monte Cara. Cf: "Notícias de S. Vicente", O Arquipélago, 21/2/1974, p. 2.

53 Oliveira, Händel, "Cabo Verde: Vitória contra a seca 9", O Arquipélago, 25/1/1973, p. 1, 3, 5.

54 Soares, Eduardo, "Cabo Verde - Ilhas perdidas no meio do mar.", O Arquipélago, 9/5/1968, p. 8.

$55 \quad I d$., ibid.p. 1,6 e 8.

56 "Foi assinada a escritura...", 23/7/1970, O Arquipélago, p. 1, 10.

57 "Cabo Verde: luta tenaz contra processos ultrapassados", O Arquipélago, 15/4/1971, p. 8.

58 Oliveira, H., "Cabo Verde. Vitória contra a seca. 9", O Arquipélago, 25/1/1973, p. 3.

59 "Foi publicado o decreto...", O Arquipélago, 17/7/1969, p. 2.

60 "Foi assinado o contrato...", O Arquipélago, 9/9/1971, p. 1, 8.

61 "A Atlântico Interplano...", O Arquipélago, 21/10/1971, p. 8.

62 "Um paraíso perdido", O Arquipélago, 19/10/1972, p.6.

63 Sobre o crescimento do turismo na Boa Vista a partir de 2007 ver, por exemplo, Bernardo 2015, Rovisco 2017.

64 "Nova Sociedade de Exploração Turística em Cabo Verde", O Arquipélago, 22/1/1970, p. 1.

65 "Problemas de Cabo verde na Emissora Nacional", O Arquipélago, 21/10/1971, p. 4.

66 Oliveira, H.,"Cabo Verde. Vitória Contra a Seca. 9", O Arquipélago, 25/1/1973, p. 3.

67 Oliveira, H., "Cabo Verde. Vitória contra a seca. 9", 25/1/1973, p. 3. Ver também "Conselho Legislativo", 18/5/1972, p. 7.

68 "Técnicos do Banco de Fomento estudam nas Canárias...", O Arquipélago, 11/4/1974, p.1; "Director do CIT", 29/4/1971, p. 1 .

69 "Um paraíso perdido", O Arquipélago, 19/10/1972, p. 6.

70 “Amnistiados pela Junta de Salvação Nacional”, O Arquipélago, 2/5/1974, p. 1.

71 "O Presídio do Tarrafal transformado numa estância turística", O Arquipélago, 6/6/1974, p.8.

72 "Exploração Turística da Zona de Chão Bom no Tarrafal", O Arquipélago, 20/6/1974, p. 8.

73 Ver, por exemplo, Lobo 2010. Para o caso espanhol ver, por exemplo, Sánchez 2004.

74 Chegou mesmo a sugerir-se que os trabalhadores dos hotéis da metrópole fossem transferidos para Cabo Verde durante o inverno. Veja-se, Rocha, Manuel, "Temas turísticos e desenvolvimento económico", O Arquipélago, 19/12/1968, p. 14.

75 Sobre as articulações entre turismo e propaganda ver, por exemplo, Cadavez (2012), sobre propaganda e turismo nas colónias portuguesas ver Silva \& Oliveira 2013, Mariz 2016. Sobre turismo e propaganda colonial no império francês, ver, por exemplo, Zytnicki e Kazdaghli, 2009.

76 "Turismo como factor de informação", O Arquipélago, 19/9/1968, p. 6.

77 Em http://turismodeislascanarias.com/es/investigacion/serie-historica-de-la-llegada-de-turistas-canarias-frontur-1997-2017/.

78 Importo aqui as palavras do poeta J. H. Oliveira Barros em "Desmontagem de Morabeza - Coimbra -73": "«Morabeza" é mendicidade de cicerone em pele e osso, / (...) «Morabeza» é ode ao conformismo / "Morabeza» é DESARMAMENTO" (1998: 257-258). 